\title{
Gastric Duplication Treated by Laparoscopy in a Child
}

\author{
Yoo Shin Choi, MD, Beom Gyu Kim, MD, Hyun Kang, MD \\ Department of Surgery, College of Medicine, Chung-Ang University, Seoul, Korea (Drs. Choi and Kim). \\ Department of Anesthesiology and Pain Medicine, College of Medicine, Chung-Ang University, Seoul, Korea (Dr. Kang).
}

\begin{abstract}
Duplication of the alimentary tract is an uncommon occurrence ( 1 of 4500 births) in pediatric patients and can affect any portion of the gastrointestinal track. The gastric duplication cysts represent $4 \%$ to $8 \%$ of all alimentary track duplications. Symptoms often occur by 2 years of age and can include nausea, vomiting, hematemesis, and vague abdominal pain. Gastric duplication cysts are typically found on the greater curvature or posterior stomach wall, are more commonly cystic than tubular, and although they are attached to the stomach, they do not typically communicate with the lumen. The treatment of choice is surgical resection.

An 8-year-old boy with intermittent upper abdominal pain visited our hospital due to acute onset pain in the lower abdominal region. Acute appendicitis with suspicion of gastric duplication was detected on computed tomography scan. Laparoscopic appendectomy was performed first. After the patient's recovery from appendectomy, we evaluated the suspected gastric lesion on the computed tomography scan. An upper gastrointestinal study revealed a communicating form of gastric duplication at the gastric greater curvature. Laparoscopic partial gastric resection was performed. In the operative field, severe adhesion between the stomach greater curvature and the surrounding tissues was observed, likely due to chronic inflammation. The suspected area of gastric duplication could be viewed by the unaided eye and identified by touch with the laparoscopic instrument. We performed a partial gastrectomy, with attachment of normal gastric tissue with a linear stapler. The patient was able to eat 2 days after the surgery and was discharged after 5 days without any complications.
\end{abstract}

Key Words: Communicating, Duplication cyst, Stomach.

Citation Choi YS, Kim BG, Kang H. Gastric duplication treated by laparoscopy in a child. CRSLS e2014.00200. DOI: 10.4293/CRSLS.2014.00200.

Copyright (C) 2014 SLS This is an open-access article distributed under the terms of the Creative Commons Attribution-Noncommercial-ShareAlike 3.0 Unported license, which permits unrestricted noncommercial use, distribution, and reproduction in any medium, provided the original author and source are credited.

Address correspondence to: Beom Gyu Kim, MD, Department of Surgery, Chung-Ang University Hospital, 224-1, Heuk Seok-Dong, Dongjak-Ku, Seoul, 156-755,

South Korea. Telephone: +82-2-6299-1545, Fax: +82-2-824-7869, E-mail: ahhaa@nate.com

\section{INTRODUCTION}

Duplication of the alimentary tract is an unusual disease, and duplications can be found anywhere from the tongue to the anus. Even more exceptional are occurrences in the stomach. ${ }^{1}$ These malformations are believed to be congenital and are formed before differentiation of the lining epithelium and are named for the organs with which they are associated. ${ }^{2}$ Duplication cysts of the stomach represent $4 \%$ of all alimentary tract duplications. Approximately $67 \%$ of gastric duplication cysts (GD) are identified with in the first year of life. ${ }^{3}$ When symptomatic, GD can present with nausea, vomiting, hematemesis, or vague abdominal pain. Occasionally, a palpable abdominal mass may be identified on physical examination, and such lesions can occasionally lead to perforation. The treatment of choice is surgical resection. The following is a description of an 8-year-old boy with a GD treated with laparoscopic partial gastric resection.

\section{CASE REPORT}

An 8-year-old boy with intermittent upper abdominal pain visited our hospital due to acute onset pain in the right lower abdominal region. Acute appendicitis with suspicion of gastric duplication was detected on computed tomography scan. Laparoscopic appendectomy was performed first. After the patient recovered from the appendectomy, we evaluated the suspected gastric lesion detected on the computed tomography scan (Figure 1). A 


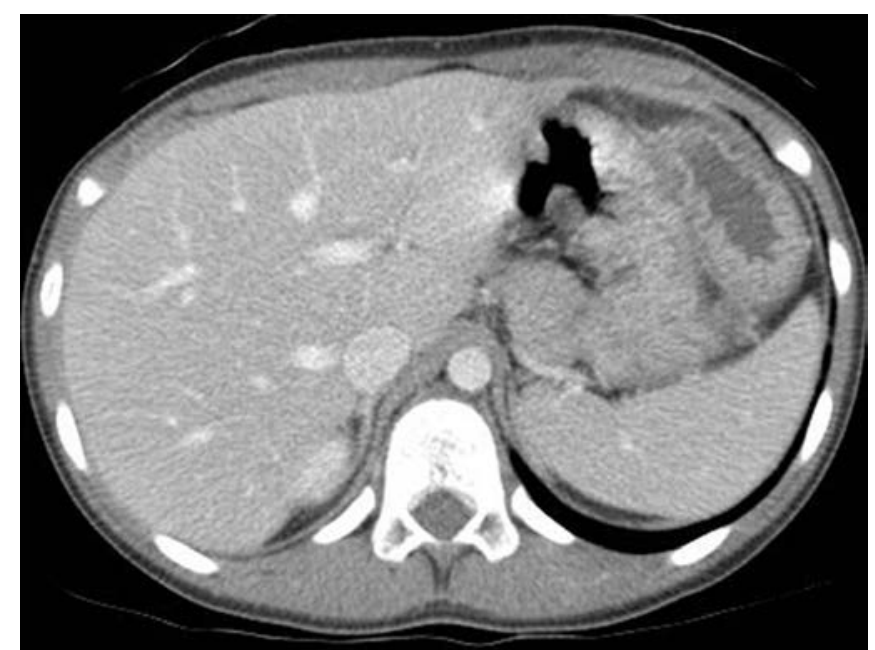

Figure 1. Contrast-enhanced computed tomography showing a stomach mimicking a cystic lesion at the superolateral aspect of stomach.

communicating-type duplication was noted at the anterior aspect of the gastric fundus on the double-contrast upper gastrointestinal study. There was extrinsic indentation of the gastric fundus with an air bubble near the duplication cyst origin, suggesting another communicating duplication cyst (Figure 2). Neither the duodenal bulb nor the C-loop was remarkable. Laparoscopic partial gastric resection was performed. In the operative field, severe adhesion between the stomach greater curvature and the surrounding tissues was observed, which was likely due to chronic inflammation. The GD could be viewed with the

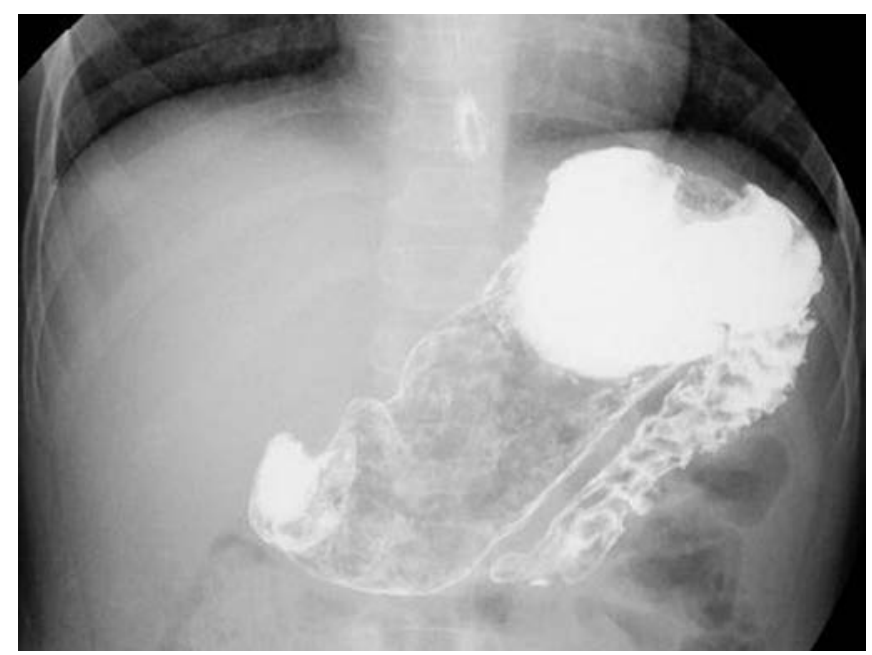

Figure 2. Double-contrast barium study showing a tubular and elongated gastric duplication cyst (communicating type) at the anterior aspect of fundus. unaided eye and could be identified by touch with the laparoscopic instrument (Figure 3). We performed partial gastrectomy with the attachment of normal gastric tissue by 3 linear staples - cartilage length: $60 \mathrm{~mm}$, stapler leg length: $3.5 \mathrm{~mm}$ (Autosuture Endo GIA, Covidien, Mansfield, Massachusetts) (Figure 4). The pathology report confirmed GD (Figure 5). The patient was able to eat 2 days after the surgery and was discharged after 5 days without any complications. One month later, we confirmed the complete removal of the gastric duplication by double-contrast upper gastrointestinal study (Figure 6).

\section{DISCUSSION}

In 1884, Reginald Fitz ${ }^{4}$ used the word duplication to describe what he thought were remnants of the omphalomesenteric duct. Thereafter, terms such as enterogenous cyst, ileum duplex, giant diverticula, and unusual Meckel diverticulum were used by different investigators to describe congenital cystic abnormalities of the gastrointestinal tract. ${ }^{5}$ Later, Gross and Holcomb ${ }^{6}$ suggested that the term duplication be used for all such anomalies, irrespective of their site, morphology, or embryologic derivations, to simplify the nomenclature.

Alimentary tract duplications are congenital anomalies that may occur anywhere along the gastrointestinal tract. Ileal duplications are most common, followed by those of the esophagus, colon, jejunum, and stomach. Nearly twothirds of GD occur in females, and more than $80 \%$ of GDs are cystic and do not communicate with the lumen of the stomach or alimentary tract. ${ }^{7}$ Most GDs occur on the greater curvature of the stomach. ${ }^{8}$ In our male patient, GD

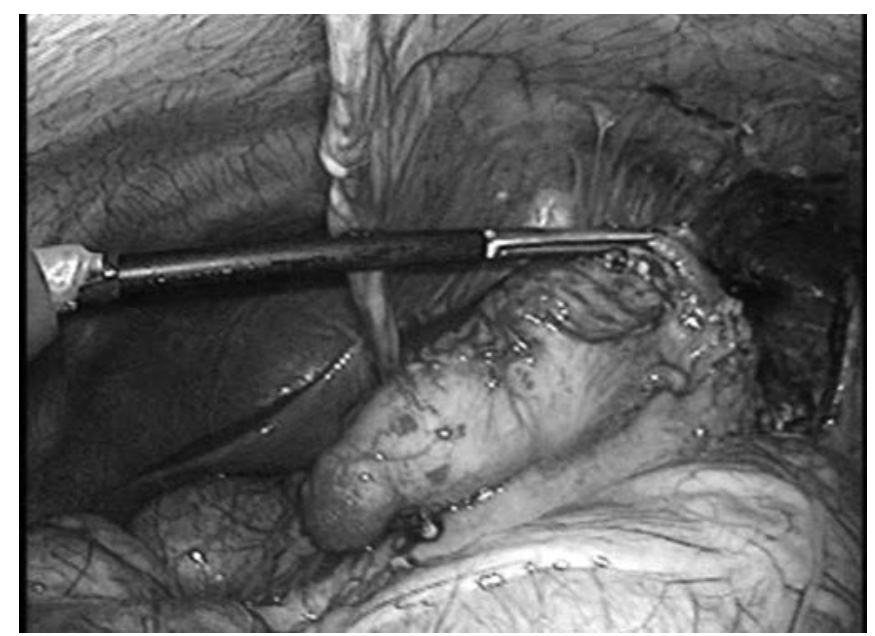

Figure 3. A duplication cyst (black arrow) was found operatively at the greater curvature of the stomach (white arrow). 


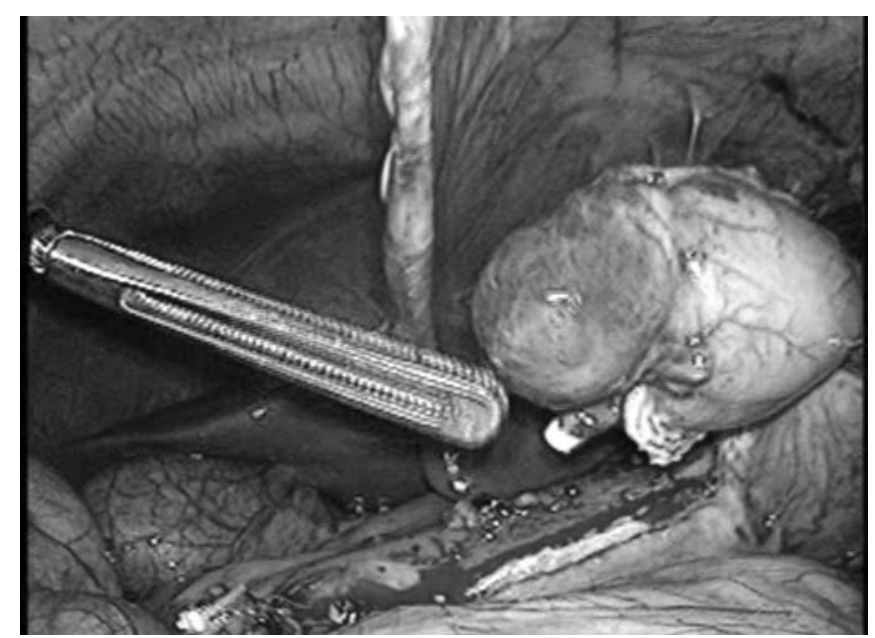

Figure 4. Resected gastric duplication cyst was found operatively at the normal stomach by a linear stapler.

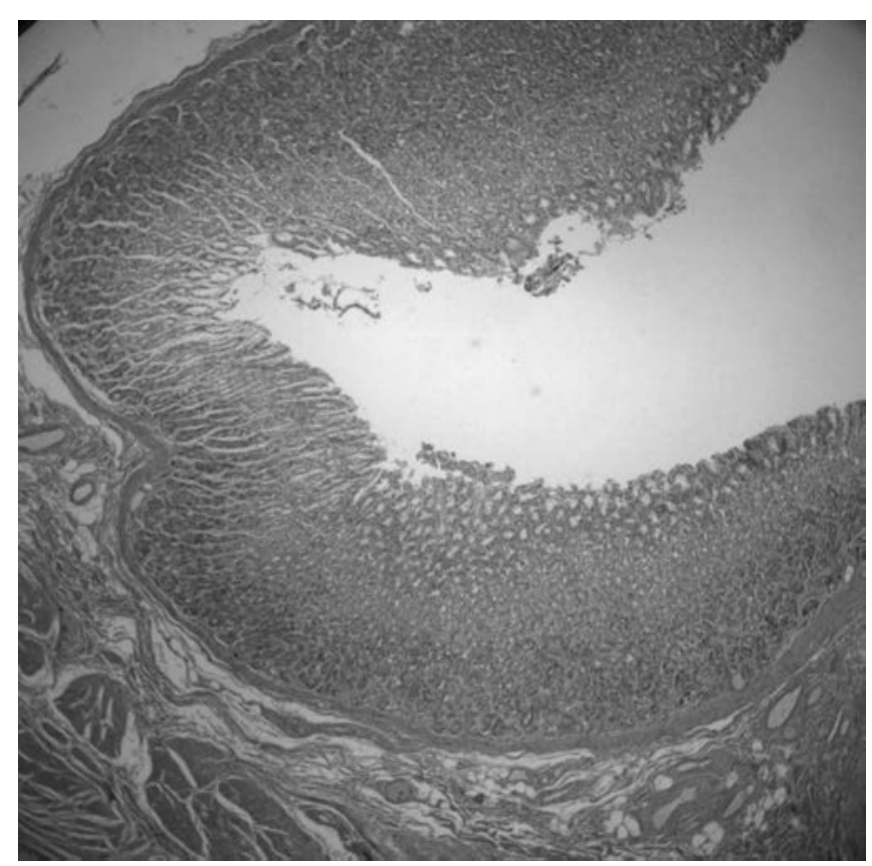

Figure 5. Pathologic finding showing a low-power view of the cystic lesion, with gastric wall (hematoxylin and eosin stain $\times 40$ ).

on the greater curvature was of the tubular type and communicated with the lumen of the stomach.

Rowling9 established several criteria for defining GD: 1) the cyst wall must be contiguous with the stomach wall; 2) the cyst is surrounded by smooth muscle, which is contiguous with that of the stomach; and 3) the cyst is lined with gastric epithelium. GDs are typically symptomatic during childhood, with 67\% diagnosed within the first

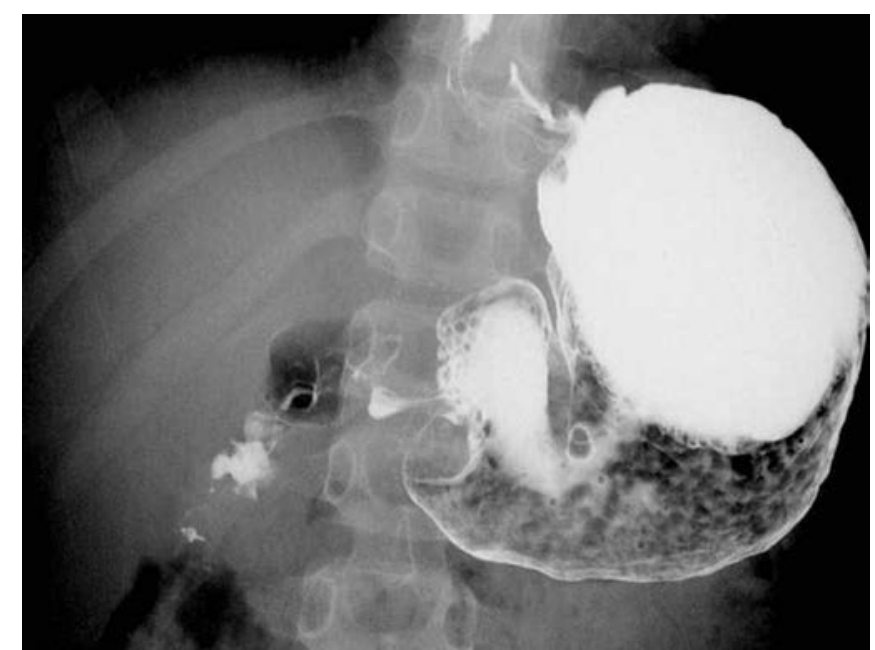

Figure 6. Double-contrast barium study showing no visible previously communicating cystic lesion.

year of life. Additional anomalies such as esophageal duplication, vertebral abnormalities, aberrant pancreas, and duodenal duplication are found in 50\% of patients with GD.?

A wide range of symptoms and signs of gastric duplication have been reported, and vary from asymptomatic to nondisease-specific presentation, e.g., vague abdominal complaints, nausea, vomiting, epigastric fullness, weight loss, anemia, dysphasia, and dyspepsia. Vomiting usually occurs due to partial or complete gastric outlet obstruction. Emergent cases have been reported as presenting with pancreatitis, hemoptysis, or gastrointestinal hemorrhage. ${ }^{10-12}$ In our case, the patient complained of only vague upper abdominal pain, which had been persistent for several years. Based on the potential for malignant transformation and reports of gastric cancer arising in GD, surgical excision is considered to be the best treatment. ${ }^{13}$ However, in the published data duplications are always benign in the pediatric population. ${ }^{8}$ Complete resection of GD is the ideal technique with both open and laparoscopic approaches. ${ }^{14}$ Unsuccessful approaches including percutaneous or endoscopic aspiration of cystic fluid have been reported, but they were associated with compilations such as fistula formation and hemorrhage. ${ }^{15}$ When the recommended complete excision is not possible, alternatives include converting both stomachs into a single stomach using a stapling device or performing a segmental gastrectomy. ${ }^{5,16}$ In this case, we were concerned about incomplete excision of the gastric duplication due to poor differentiation between the normal stomach and GD. We prepared a gastrofiberscope to identify the lesion 
and normal stomach for the operation. If the scope is located in the normal stomach, when viewed by laparoscopy, the transillumination light of the gastrofiberscope is not detected in GD. In the operative field, the duplication cyst was reddish, edematous, and harder than the normal stomach when touched by the laparoscopic instrument; the GD was easily identified and excised, and some additional normal stomach was excised to achieve complete removal.

In conclusion, we report a rare case of a communicating GD that developed in childhood and was treated by laparoscopic partial gastrectomy without any complications.

\section{References:}

1. Theodosopoulos T, Marinis A, Karapanos K, et al. Foregut duplication cysts of the stomach with respiratory epithelium. World J Gastroenterol. 2007;13(8):1279-1281.

2. Cunningham SC, Hansel DE, Fishman EK, Cameron JL. Foregut duplication cyst of the stomach. J Gastrointest Surg. 2006; 10(4):620-621.

3. Blinder G, Hiller N, Adler SN. A double stomach in an adult. Am J Gastroenterol. 1999;94(4):1100-1102.

4. Fitz RH. Persistent omphalo-mesenteric remains: their importance in the causation of intestinal duplications, cyst formation, and obstruction. Am J Med Sci. 1884;88:30-57.

5. Holcomb GW 3rd, Gheissari A, O'Neill JA Jr, Shorter NA, Bishop HC. Surgical management of alimentary tract duplications. Ann Surg. 1989;209(2):167-174.

6. Gross RE, Holcomb GW Jr, Farber S. Duplications of the alimentary tract. Pediatrics. 1952;9(4):448-468.
7. Wieczorek RL, Seidman I, Ranson JH, Ruoff M. Congenital duplication of the stomach: case report and review of the English literature. Am J Gastroenterol. 1984;79(8):597-602.

8. Armstrong CP. Miscellaneous conditions of the stomach. In: Taylor, TV, Williamson, RCN, Walker A, eds. Upper Digestive Surgery. New York, NY: WB Sanders; 1999;652-655.

9. Rowling JT. Some observations on gastric cysts. Br J Surg. 1959;46(199):441-445.

10. Katz W, Annessa G, Read RC. Gastric duplication with pancreatic communication: presenting as pancreatitis. Minn Med. 1967;50(8):1175-1179.

11. Menon P, Rao KL, Saxena AK. Duplication cyst of the stomach presenting as hemoptysis. Eur J Pediatr Surg. 2004;14(6): 429-431.

12. Stephen TC, Bendon RW, Nagaraj HS, et al. Antral duplication cyst: a cause of hypergastrinemia, recurrent peptic ulceration, and hemorrhage. J Pediatr Gastroenterol Nutr. 1998;26(2): 216-218.

13. Kuraoka K, Nakayama H, Kagawa T, Ichikawa T, Yasui W. Adenocarcinoma arising from a gastric duplication cyst with invasion to the stomach: a case report with literature review. J Clin Pathol. 2004;57(4):428-431.

14. Machado MA, Santos VR, Martino RB, et al. Laparoscopic resection of gastric duplication: successful treatment of a rare entity. Surg Laparosc Endosc Percutan Tech. 2003;13(4):268-270.

15. Ferrari AP Jr, Van Dam J, Carr-Locke DL. Endoscopic needle aspiration of a gastric duplication cyst. Endoscopy. 1995;27(3): $270-272$.

16. Izzidien al-Samarrai AY, Crankson SJ, Sadiq S. The use of mechanical sutures in the treatment of gastric duplications. $Z$ Kinderchir. 1989;44(3):186-187. 